\title{
Los desafíos de la comunicación virtual en tiempos de pandemia
}

\section{The challenges of virtual communication in times of pandemic}

\author{
Azucena Wendy Montalva Miñan* \\ Escuela de Ciencias de la Comunicación, \\ Universidad de San Martín de Porres, Perú
}

\section{Resumen}

El presente trabajo tiene como finalidad analizar la comunicación virtual en el contexto de pandemia, al igual que la interacción mediada por la tecnología donde se comienza a gestar una cultura virtual. De esta manera, la comunicación virtual se torna vigente y requiere ser estudiada para comprender los fenómenos sociales que surgen al instaurar esta forma de comunicación en la vida cotidiana de la sociedad mundial. Las relaciones interpersonales han mutado, la retroalimentación comunicativa cobra otros matices de desarrollo en este nuevo mundo virtual que viene cambiando patrones comunicativos.

Palabras clave: comunicación virtual, interacción, cultura virtual.

\begin{abstract}
The present work aims to analyze virtual communication in the context of a pandemic, as well as the interaction mediated by technology, where a virtual culture begins to take shape. In this way, virtual communication becomes a current topic that needs to be studied to understand the social phenomena that arise when establishing this form of communication in
\end{abstract}

Este es un artículo Open Access bajo la licencia Creative Commons Atribución-NoComercial-Compartirlgual 4.0 
everyday life of world society. Interpersonal relationships have mutated, and the communicative feedback has other developmental aspects in this new virtual world that is changing the communication patterns.

Keywords: virtual communication, interaction, virtual culture.

\section{Introducción}

El mundo aún se encuentra en medio de una pandemia que, desde que se declaró como tal por la Organización Mundial de la Salud (2020), obligó a las autoridades de los países del orbe a tomar medidas drásticas, que incluyen distanciamiento social y cierre de lugares; se sustituyó el contacto personal por el virtual con la finalidad de evitar el aumento de contagios por la COVID19. Las labores diarias pasaron a desarrollarse de manera virtual, modificando las formas de comunicación entre las personas en el trabajo, las clases, etc.

Además, debido al confinamiento social -necesario para proteger la saludsurgieron nuevos retos y experiencias en la dimensión virtual, exigiendo cambios radicales en nuestras expectativas y perspectivas.

Krebs (2020) cuestiona:

¿Qué habría sido de nosotros en esta pandemia sin esa dimensión virtual que todos ahora nos vemos obligados a vivir? Hemos logrado escapar del confinamiento físico al que nos ha sometido el virus para continuar en contacto desde nuestro aislamiento obligatorio, y ello implica un costo. (párr. 9)

Es relevante señalar la dimensión social de la comunicación en estos tiempos de pandemia, ya que es una necesidad humana mantener vínculos con otras personas, interactuar, socializar, entrar en contacto, relacionarse, compartir, poner en común. De hecho, interacción y comunicación tienen conceptos interdependientes ya que ninguno puede existir sin el otro, y por consecuencia, el ser humano sin ninguno de estos.

De igual forma, el entorno virtual se hace más valioso cuando nos facilita la comunicación, siendo intermediario, conectando a las personas. Esta 
interacción virtual promueve la construcción de conocimientos masivos, aprendizajes útiles para crear redes de interacción social.

\section{La comunicación virtual}

La comunicación virtual se desarrolla en un entorno digital que, a través de espacios virtuales, instaura relaciones interpersonales que van más allá de la función de trasmitir datos entre emisor y receptor; se puede señalar entonces que la comunicación virtual es dinámica y se caracteriza por sincronizar y generar reciprocidad en los mensajes. De manera que la comunicación virtual crea el escenario para tener relaciones interpersonales donde la interacción mutua es una característica básica.

La comunicación virtual utiliza como medio a la conectividad de la tecnología para realizar el intercambio de información «bajo parámetros: espacio, tiempo, conectividad y valor; que le dan sentido al acto comunicativo, puesto que aportan un sentido nuevo a la comunicación, en la que se establece un proceso relacional que intervienen en la comunicación» (Ruiz, 2006, p. 117). En contraste, para Martínez y Solano (2003, p. 18) es «el proceso mediante el cual se crea, intercambia y comparte información en entornos virtuales generados por los sistemas computacionales que son producto de la fuerza intangible del advenimiento tecnológico».

Ambas aproximaciones definen a la comunicación desde dos aspectos: tecnológico y funcional. El intercambio de información mediante soportes tecnológicos hace posible la mediación en la comunicación.

Cabe señalar que las tecnologías de la información y las comunicaciones (TIC) han logrado que la comunicación evolucione, favoreciendo las relaciones dialógicas entre las personas, fortaleciendo la inteligencia colectiva y el aprendizaje colaborativo.

De esta manera, la transformación virtual permite el papel ágil entre el emisor y el receptor, que ahora pasan a ser intérpretes de un nuevo ambiente comunicativo. En esta nueva plataforma las ideas, el texto y el discurso en la red se caracterizan por ser rápidos, asincrónicos o sincrónicos y muy flexibles para el entendimiento comunicativo. 
La comunicación virtual hace que la comunicación supere las distancias y facilita el acceso a la información. Le permite a las personas conocer y vincularse entre ellas. Ahora bien, también genera que se pierda el vínculo cara a cara, que es la base del proceso comunicativo interpersonal no virtual. Puede considerarse que esto es lo que más se extraña en tiempos de pandemia.

Por esta razón la comunicación virtual en tiempos de pandemia nos puede dar la falsa sensación de estar comunicándonos como si estuviésemos cara a cara. Pero no es así, ya que muchas veces no hay contacto visual, podemos ver los rostros, pero no nuestros ojos, no compartimos el mismo espacio y la comunicación corporal está muy limitada.

De modo que para suplir estas limitaciones en la comunicación paraverbal, es recomendable utilizar el lenguaje no verbal: la entonación, las pausas y el lenguaje corporal como gestos, postura, dar las explicaciones necesarias para que el mensaje llegue, utilizar el tono de voz adecuado, pedir aclaraciones y usar un lenguaje más emocional.

Por consiguiente, en la comunicación virtual debemos trasmitir la información optimizando nuestras habilidades comunicativas y emocionales; priorizar pensar en lo que queremos transmitir y no olvidarnos de algo fundamental: la comunicación no verbal, aspecto importante para tomar en cuenta todo lo que verbalizamos en el proceso comunicativo, nuestra voz y todo lo que representa, así como el lenguaje corporal e imagen a través de la pantalla.

La comunicación virtual produce un desplazamiento de la presencia física del interlocutor, e irrumpe en el lenguaje icónico. El lenguaje oral es un acto de comunicación que precisa de lo físico: voz, gestos, cuerpo; logrando la convivencia en un entorno que no es natural pero en el que la tecnología es vital para la comunicación del ser humano.

\section{Interactividad en la comunicación virtual}

La interactividad en la comunicación virtual define el proceso comunicativo, donde se realiza una participación activa y recíproca de sus 
actores. La interactividad se entiende como una propiedad de los medios tecnológicos que intervienen en los procesos comunicativos.

El concepto de interactividad es una respuesta preprogramada dentro de un sistema; en ese caso el mensaje que recibimos hace referencia al inmediatamente anterior o a una serie de mensajes intercambiados antes. Hay interactividad en las comunicaciones sujeto-sujeto pero también en los intercambios entre un sujeto y un dispositivo tecnológico. En este segundo ejemplo la interactividad se desarrolla en la interfaz, que se podría definir como el lugar de la interacción. (Scolari, 2013, p. 94)

Por otra parte, la interactividad permite al usuario comprobar, crear, modificar y enviar contenidos a su propio ritmo, donde los medios virtuales generan ambientes adaptables; para ello, el medio tecnológico es el soporte facilitador del coloquio y no solo el trasmisor de datos. En la interactividad se puede obtener el control sobre el desarrollo de divulgación de los contenidos, dimensión que afecta la reciprocidad de mensajes pues direcciona la cadencia y la sucesión de las conversaciones.

El usuario como dominador del formato digital es quién propone la ruta para definir la secuencia dialógica; y la plataforma virtual, es el medio que favorece que dicho usuario pueda orientar lo que desea enviar o recibir. El control lo tiene quien envía y recibe la comunicación. No solo uno tiene el poder. Así se democratiza la comunicación mediante la interactividad.

La interactividad en el entorno de la comunicación virtual realiza la emisión de los mensajes, permite examinar su sentido, sucesión y significado. No obstante, la acción entre ambas, interactividad y comunicación virtual afectan todo el proceso comunicativo, desarrollando conductas sociales.

La interactividad desde la comunicación mediada por computador se define a partir de dos condiciones: 1 . Reciprocidad en los mensajes y 2. Sincronización de los elementos que componen el espacio (plataformas virtuales) para garantizar el flujo comunicativo. (Marshall, 1996, p. 65) 
La interactividad explica toda una cultura social mediatizada por las plataformas virtuales que evolucionan con el tiempo.

\section{Cultura virtual}

Desde los primeros días del 2020 la humanidad entró abruptamente al mundo virtual, a consecuencia de la pandemia originada por la COVID-19; hecho que no se olvidará y marcará un antes y un después en la memoria de las personas, sobre todo porque nos vimos forzados a convivir en el mundo virtual. Gracias a la tecnología el mundo pudo estar conectado, unido y evitar el contagio.

Cabe mencionar que pasar mucha parte del día conectados creó hábitos y costumbres en el entorno familiar, laboral y social, concibiendo una cultura tecnológica que comenzó a plasmar nuevas formas de producción e interacción, así como respuestas culturales creativas y novedosas.

Muchos aspectos de la relación con la tecnología deben ser analizados si lo que se desea es obtener un entendimiento de sus efectos; por ejemplo, la postura frente a la tecnología, la concepción del mundo virtual, las formas de organizar el trabajo, el tiempo libre y las actividades en general.

Nos encontramos inmersos en plena mutación histórica. Los cambios culturales son muy profundos. Incluso nosotros mismos nos hemos convertido en una especie mutante que tiene que hacer frente a retos y cambios continuos. La rapidez y la intensidad de los cambios a los cuales asistimos nos impiden, a menudo, tener una idea precisa de su alcance. Nos falta perspectiva. (Barico, 2008, p. 34)

De este modo, se evidencia que el cambio cultural que estamos presenciando está mediado por la celeridad e intensidad, con características audiovisuales y de conectividad, que rompen las barreras y facilitan el intercambio y la hibridación cultural. Este cambio rompe barreras que históricamente han confinado las culturas en determinados espacios y favorece el intercambio y la hibridación cultural. 
Por consiguiente, el desarrollo cultural virtual logra hacer resurgir la vieja idea de la aldea global de McLuhan (como se citó en Pérez, 2012) y da un fuerte empuje a la globalización cultural virtual.

Uno de los aspectos más influenciados por la cultura virtual es la vida cotidiana. Internet ofrece la facultad de desarrollar un sistema de relaciones sociales con personas con las que no se comparte espacio ni tiempo, pero que gracias a la conexión se tienen muy cerca.

Dicho de otro modo, Internet provee una interactividad enriquecedora, constante en el tiempo; donde la distancia física no es una barrera para comunicarse. En este sentido, la distancia ya no es un obstáculo comunicativo.

Es importante mencionar que la comunicación virtual como señala Ruiz (2006), favorece el intercambio de información y aporta un nuevo sentido comunicativo. Asimismo, Martinez y Solano (2003) enfatizan en que dicha comunicación virtual es creada por una necesidad de comunicación por parte del ser humano frente al futuro inmediato que se lo exige. Ambas definiciones aportan a la comprensión de la comunicación virtual, que utiliza la conexión a Internet para llevar a cabo su función de poner en común, de crear vínculos y de informar.

De acuerdo con lo dicho sobre la comunicación virtual, Scolari (2013) considera que la interactividad es una respuesta frente al mensaje recibido e intercambiado desarrollado en una interfaz, creando así una cultura virtual donde «el hacer» va formando nuevos estilos de interacción, conversación, modos de vida mediante la comunicación virtual.

Con respecto a la cultura virtual se evidencian experiencias e interacciones que transforman la vida social actual, lo que permite nuevas formas de expresión, hábitos y costumbres.

Para concluir, es importante reflexionar en estos tiempos de pandemia acerca de la comunicación virtual y las grandes oportunidades que ofrece en términos de eficiencia y progreso, pero también, en los complejos desafíos que acarrea. Es necesario ampliar los estudios sobre comunicación virtual, interacción virtual y cultura virtual con relación a los medios de comunicación digital. 


\section{Referencias}

Baricco, A. (2008). Los bárbaros. Ensayo sobre la mutación. Anagrama.

Krebs, V. (2020, 24 de abril). Cuarentena virtual, más conectados que aislados. El Comercio. https://elcomercio.pe/ eldominical/cuarentena-virtual-mas-conectadosque-aislados-internet-aislamiento-cuarentena-virtualidad-noticia/

Marshall, Mc. (1996). Comprender los medios de comunicación. Las extensiones del ser humano. PAIDOS. http:/l semioticaderedes-carlon.com/wpcontent/uploads/2018/04/McLuhan_Marshall Comprender_los_medios_de_comunicacion.pdf

Martínez, F. y Solano, I. (2003). El proceso comunicativo en situaciones virtuales. En F. Martínez (comp.), Redes de comunicación en la enseñanza (pp. 13-29). Barcelona. Paidos.

Organización Mundial de la Salud (OMS). (2020). Los nombres de la enfermedad por coronavirus (COVID-19) y del virus que la causa. https://www.who.int/es/emergencies/diseases/novel-coronavirus-2019/technicalguidance/naming-the-coronavirus-disease-(covid-2019)-and-the-virus-that-causes-it

Ruiz, J. A. (2006). Comunicación virtual: elementos y dinámicas (vol. 2). Visión Libros.

Scolari, C. (2013). Hipermediaciones: elementos para una teoría de la comunicación digital interactiva. Editorial Gedisa.

Pérez, T. A. (2012). Marshall Mcluhan, las redes sociales y la aldea global. Revista educación y tecnología, (2), 8-21. 